\title{
Maternal depression, stress and feeding styles: towards a framework for theory and research in child obesity ${ }^{\text {th }}$
}

\author{
Ana F. El-Behadli ${ }^{1}$, Carla Sharp ${ }^{2}$, Sheryl O. Hughes ${ }^{3}$, Ezemenari M. Obasi ${ }^{4}$ and Theresa A. Nicklas ${ }^{3 *}$ \\ ${ }^{1}$ Eliot-Pearson Department of Child Study and Human Development, Tufts University, 105 College Avenue, \\ Medford, MA 02155, USA \\ ${ }^{2}$ Department of Psychology, University of Houston, 126 Heyne Building, Houston, TX 77204, USA \\ ${ }^{3}$ Department of Pediatrics, Baylor College of Medicine, USDA/ARS Children's Nutrition Research Center, \\ 1100 Bates Avenue, Houston, TX 77030, USA \\ ${ }^{4}$ EPSY/Counseling Psychology, University of Houston, 491 Farish Hall, Houston, TX 77204, USA \\ (Submitted 22 November 2013 - Final revision received 24 July 2014 - Accepted 18 August 2014)
}

\begin{abstract}
Against the background of rising rates of obesity in children and adults in the USA, and modest effect sizes for obesity interventions, the aim of the present narrative review paper is to extend the UNICEF care model to focus on childhood obesity and its associated risks with an emphasis on the emotional climate of the parent-child relationship within the family. Specifically, we extended the UNICEF model by applying the systems approach to childhood obesity and by combining previously unintegrated sets of literature across multiple disciplines including developmental psychology, clinical psychology and nutrition. Specifically, we modified the extended care model by explicitly integrating new linkages (i.e. parental feeding styles, stress, depression and mother's own eating behaviour) that have been found to be associated with the development of children's eating behaviours and risk of childhood obesity. These new linkages are based on studies that were not incorporated into the original UNICEF model, but suggest important implications for childhood obesity. In all, this narrative review offers important advancements to the scientific understanding of familial influences on children's eating behaviours and childhood obesity.
\end{abstract}

\section{Key words: Childhood obesity: Maternal depression: Life stress: Feeding styles: Eating behaviours: Dietary intakes}

Over the past three decades, the percentage of adults who are obese has doubled; the percentage of children who are overweight has doubled; and the percentage of adolescents who are overweight has tripled. Two-thirds of US adults are overweight or obese. An estimated one-third of US children and adolescents are overweight, while $17 \%$ are obese ${ }^{(1)}$. Children who are obese tend to become obese adults ${ }^{(2-4)}$. Obesity contributes to the major causes of death in the USA, including atherosclerotic CVD, type 2 diabetes and some forms of cancer ${ }^{(5-7)}$. Obesity affects quality of life, increases medical costs and increases job absenteeism in adults ${ }^{(8-13)}$; direct and indirect costs associated with obesity in adults are estimated at $\$ 209$ billion or $20.6 \%$ of US healthcare expenditures $^{(13)}$. Obesity in both children and adults is most prevalent among ethnic minority groups ${ }^{(14-17)}$.
The extended UNICEF care model is a framework that can be used to identify factors that affect nutrition in infancy and early childhood. This framework identifies three major sets of factors that influence child nutrition: food/economic resources; caregiver resources; community health resources $^{(18)}$. Recently, Wachs ${ }^{(19)}$ has proposed a revised version of the extended UNICEF care model to expand the influence of three caregiver resources to include maternal education, intelligence and depression, as well as child characteristics. Wachs' revised version takes a systems approach to understand how different elements are linked to determine undernutrition in children. Wachs emphasises the importance of understanding the factors that influence outcome variability as well as the different degrees and natures of these linkages. His review included a brief

Abbreviations: SES, socio-economic status; CVD, cardiovascular disease.

*Corresponding author: T. A. Nicklas, email tnicklas@bcm.edu

This article was published as part of the WALTHAM International Nutritional Sciences Symposium Proceedings 2013.

This paper was published as part of a supplement to British Journal of Nutrition, publication of which was supported by an unrestricted educational grant from Mars Incorporated. The papers included in this supplement were invited by the Guest Editor and have undergone the standard journal formal review process. They may be cited. 
discussion on how a systems perspective can also apply to the study of childhood obesity.

Maternal education, maternal intelligence and maternal depression are the three caregiver resources central to Wachs' revised version of the model. Wachs added these three caregiver resources because they are both interlinked and linked to other dimensions of the model. Wachs defined maternal education as the years of schooling achieved by the mother in the public school system. Studies have shown that higher levels of maternal education are linked to better quality and quantity of children's diet ${ }^{(20)}$, as well as to an increase in access to economic resources ${ }^{(21)}$. Additional studies have indicated that maternal education levels might mediate the process through which family income influences child nutrition $^{(22)}$. Moreover, mothers with higher education levels were found to more likely have a greater variety of coping strategies to supplement family nutrition under times of financial stress ${ }^{(23)}$. Finally, higher maternal education levels were found to be related to better maternal health and nutritional status. This is important because mothers with poor health or nutritional status are less likely to provide adequate nutrition for their family ${ }^{(24)}$

Lower education levels have also been reported to be associated with childhood obesity ${ }^{(25-27)}$, especially in children with obese mothers ${ }^{(28)}$. Similarly, higher levels of parental education may serve as a protective factor against childhood obesity $^{(29,30)}$. However, the relationship between parental education and childhood obesity may be moderated by ethnicity $^{(31)}$ and culture ${ }^{(32)}$.

The relationship between parental education and the risk of childhood obesity may be a function of parental perceptions or parent-child interactions. For example, mothers with higher levels of education may be more accurate in their perception of their children's weight compared with those with lower levels of education ${ }^{(25,29)}$. Lower maternal education levels have been reported to be related to more prompts for children to eat novel foods, which has been found to be a predictor of higher BMI in children ${ }^{(28)}$. Some studies suggest an inverse relationship between parental education and dietary fat intake ${ }^{(33-35)}$ and selection of highfat foods ${ }^{(36)}$ by children.

Maternal intelligence was also added as a caregiver resource to Wachs' revised model. Wachs defined intelligence as an individual's ability to both modify and adapt to his or her environment. Studies have shown an association between higher levels of schooling and higher levels of intellectual performance. Wachs argued that higher intellectual functioning might act as a mediator in the aforementioned relationship between maternal education and child nutrition.

Maternal depression was the third caregiver resource added to the model by Wachs. Depressed mothers exhibit disturbed patterns of mother-infant interactions (i.e. reduced sensitivity, responsivity and interaction). These characteristics may limit the ability of a mother to respond appropriately when feeding her child ${ }^{(37,38)}$. Moreover, in families of low socio-economic status (SES), restriction of food choices requires greater caregiver involvement (e.g. providing the best possible nutrition at the lowest cost). Such active involvement is less likely to occur in depressed mothers ${ }^{(39)}$.

Wachs included social support as a mechanism that affected caregiver resources. Social support was defined as the mother's social network of family and friends, who through their interactions can enhance her ability to function under stressful conditions. Studies have shown that higher levels of social support positively affect mothers' ability to care for their family during times of economic stress ${ }^{(20)}$. Women with lower levels of social support were found to be at an increased risk of maternal depression ${ }^{(20)}$.

Finally, Wachs incorporated child characteristics into the extended UNICEF care model. The following four child characteristics were included: health; sex; age; temperament. These child characteristics interact with the other factors in the model to affect child nutrition. For example, individual differences in child temperament may directly influence child nutrition and moderate or mediate the influence of family and caregiver resources on child nutrition. Furthermore, there is evidence suggesting that maternal feeding practices vary depending on the weight of children ${ }^{(40)}$. Mothers who perceived their daughters to be overweight reported using more restrictive feeding practices. Similarly, mothers reported using more pressure in feeding when daughters were thinner.

Overall, these patterns of findings show that other factors beyond financial resources and food availability influence child nutrition and these include many non-economic factors. Although Wachs' proposed revision offers mediating and moderating links between different elements of the extended UNICEF care model, certain limitations prevent the model from being a complete framework for childhood nutrition and subsequently childhood obesity.

\section{Linking Wachs' version of the extended UNICEF care model to childhood obesity: emotional climate of the parent-child relationship}

The effectiveness of current obesity programmes (based on published reviews) is quite modest ${ }^{(41-44)}$, with many programmes demonstrating no significant reduction in weight. Including family factors in our understanding of the interrelated constructs affecting childhood obesity is clearly needed so that effective obesity prevention programmes can be developed. An important family construct that has not been included in Wachs' revised version of the extended UNICEF care model is the emotional climate of the parent-child relationship. Parents are the gatekeepers within their households making certain foods available/accessible or not and providing modelling while consuming those foods in front of their children ${ }^{(45,46)}$. Furthermore, it is well known that parent-child feeding interactions affect children's weight status ${ }^{(47)}$. However, the emotional quality of the parent-child relationship may play an important role in what is transmitted to the child within the family context, especially when it comes to feeding.

Certain factors may affect the quality of the parent-child relationship. Depression (which already appears in Wachs' revised model) clearly plays a role in parent-child interactions $^{(48)}$ and is commonly observed among mothers 
of young children ${ }^{(48)}$. However, other risk factors (as has been mentioned above) such as stress, culture and low SES interact with maternal depression to affect children. Women of ethnic minorities and low SES exhibit the highest rates of maternal depression as they more frequently experience negative life events and have fewer resources to cope with these events $^{(49-54)}$. These mothers are at a risk of low self-esteem $^{(55)}$, chronic stressors and depressive symptoms ${ }^{(49)}$ and providing inconsistent, inappropriate discipline ${ }^{(56,57)}$. Furthermore, maternal depression has been reported to be associated with increased pressure on daughters to eat more food $^{(40)}$ and higher use of maternal restrictive feeding ${ }^{(40,58)}$, which may play a role in childhood obesity.

The aim of the present narrative review paper is to extend the UNICEF care model to focus on childhood obesity and its associated risks with an emphasis on the emotional climate of the parent-child relationship within the family. Elevated levels of familial risk (such as stress and depression) can interfere with parents' abilities to provide appropriate parenting/ feeding within the family context ${ }^{(48)}$. Based on Wachs' review, we modified the extended care model by explicitly integrating new linkages (i.e. parental feeding styles, stress, depression and mother's own eating behaviour) that have been found to be associated with the development of children's eating behaviours and risk of childhood obesity (Fig. 1). This new model, applying the systems approach to childhood obesity, combines sets of literature across multiple disciplines including developmental psychology, clinical psychology and nutrition. These new linkages are based on studies that were not incorporated in the original UNICEF model, but suggest important implications for childhood obesity. This review paper focuses on two narrative reviews: (1) relationships between parental feeding styles and children's eating behaviours and weight status (Table 1) and (2) relationships between maternal mental health and parental feeding behaviours (Table 2). Other linkages are discussed briefly. These extended links are depicted in a reformulation of Wachs' model shown in Fig. 1. This research offers important advancements to the scientific understanding of familial influences on children's eating behaviours and weight status.

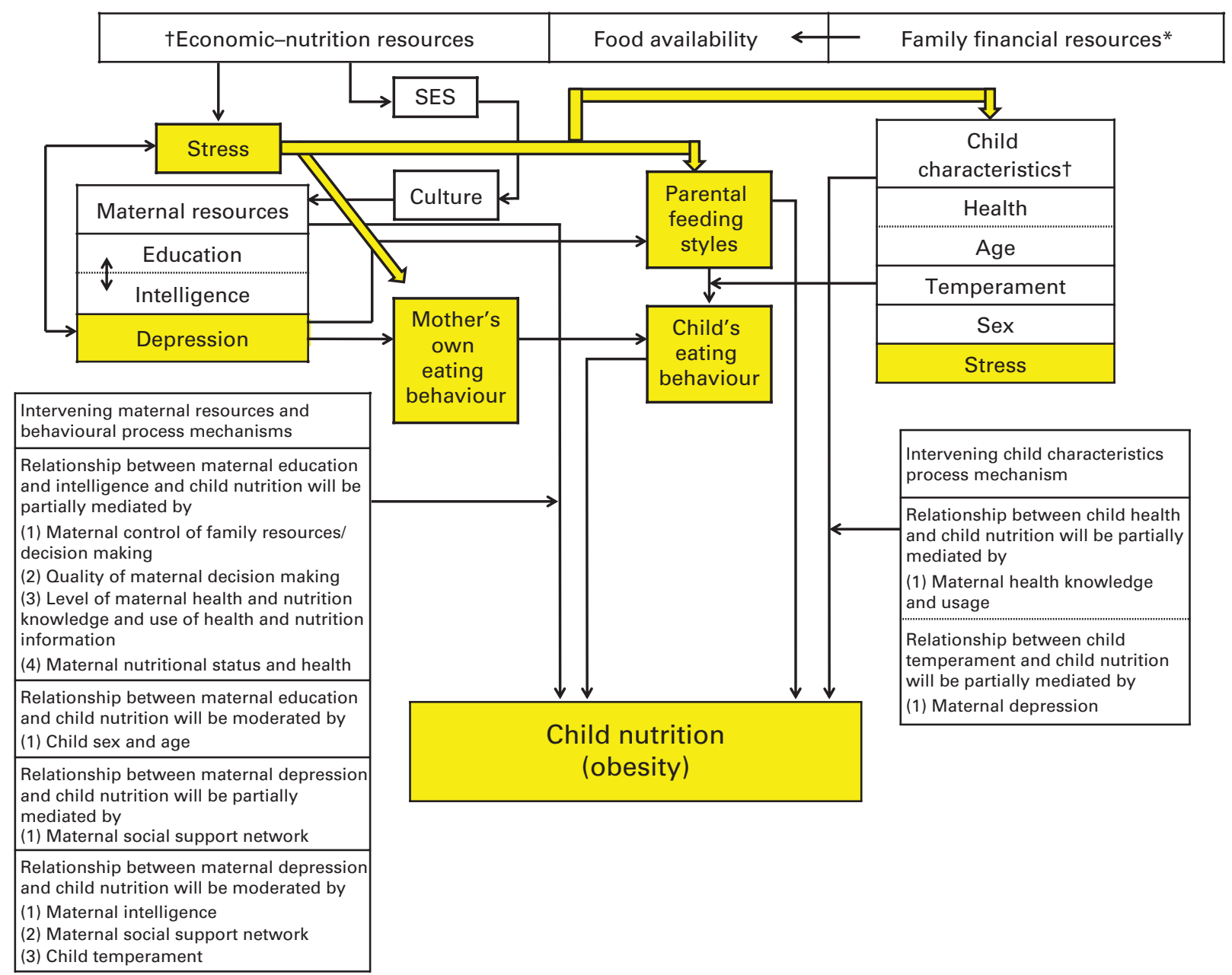

Fig. 1. Adaptation of the extended UNICEF care model. * Family financial resources will mediate the influence of maternal education and moderate the influence of social support. †Child age may moderate the influence of family economic-nutrition resources. Double-headed arrows indicate bidirectional influences and arrows intersecting other arrows indicate mediation of moderation processes. 


\section{N British Journal of Nutrition}

Table 1. Relationships between parental feeding styles and children's eating behaviours and weight status

\begin{tabular}{clllll}
\hline Author(s) & Study design & Subjects & $\begin{array}{l}\text { Feeding } \\
\text { measure }\end{array}$ & $\begin{array}{l}\text { Other } \\
\text { assessment tools }\end{array}$ & Covariates \\
\hline $\begin{array}{c}\text { Hughes } \\
\text { et al. }{ }^{(71)}\end{array}$ & $\begin{array}{c}\text { Questionnaires, } \\
\text { cross-sectional } \\
\text { study, USA }\end{array}$ & $\begin{array}{c}\text { 231 parent-child } \\
\text { dyads; low-income } \\
\text { families with } \\
\text { preschoolers } \\
\text { (130 Hispanic and } \\
\text { 101 African American) }\end{array}$ & CFSQ & CFQ, PDI and BMI & None \\
& & & & \\
& & & & \\
& & & &
\end{tabular}

\begin{tabular}{|c|c|c|}
\hline $\begin{array}{l}\text { Hughes } \\
\text { et al. }{ }^{(73)}\end{array}$ & $\begin{array}{l}\text { Questionnaires, } \\
\text { cross-sectional } \\
\text { study, USA }\end{array}$ & $\begin{array}{l}718 \text { parent-child dyads; } \\
\text { low-income families } \\
\text { with preschoolers } \\
\text { (209 Hispanic, } \\
309 \text { African American, } \\
\text { and } 200 \text { White) }\end{array}$ \\
\hline $\begin{array}{l}\text { Hughes } \\
\text { et al. }{ }^{(74)}\end{array}$ & $\begin{array}{l}\text { Observations and } \\
\text { questionnaires, } \\
\text { cross-sectional } \\
\text { study, USA }\end{array}$ & $\begin{array}{l}177 \text { parent-child dyads; } \\
\text { low-income families } \\
\text { with preschoolers } \\
\text { (ninety-seven African } \\
\text { American and } \\
\text { eighty Hispanic) }\end{array}$ \\
\hline $\begin{array}{l}\text { Tovar } \\
\quad \text { et al. }{ }^{(75)}\end{array}$ & & $\begin{array}{l}383 \text { immigrant } \\
\text { mother-child dyads } \\
\text { (138 Brazilian, } \\
131 \text { Haitian and } \\
114 \text { Latino). } \\
\text { Children's average } \\
\text { age was } 6 \text { years }\end{array}$ \\
\hline $\begin{array}{r}\text { Hennessy } \\
\text { et al. }{ }^{(72)}\end{array}$ & $\begin{array}{l}\text { Questionnaires, } \\
\text { cross-sectional } \\
\text { study, USA }\end{array}$ & $\begin{array}{l}\text { Ninety-nine parent-child } \\
\text { dyads (twenty-two } \\
\text { Hispanic, forty-eight } \\
\text { African American and } \\
\text { twenty-nine White); } \\
\text { low-income rural sample } \\
\text { with children aged } \\
6-11 \text { years }\end{array}$ \\
\hline
\end{tabular}

CFSQ CBQ, PANAS Parental ethnicity, education, and $\mathrm{BMI}$

CFSQ

CFSQ

CFSQ

age, BMI, and affect

and child age, sex

and temperament

Home observation coding system observed behavioural feeding practices and BMI CES-D, PSS and BMI acculturation (two questions)

\section{CFQ, PDI and}

None - global affect ratings and feeding practices were not associated with parental $\mathrm{BMI}$ and child $\mathrm{BMI}$ and sex; length of the meal occasion was controlled for

Maternal ethnicity, education, age, BMI, perceived stress, depression, and acculturation and child age and sex

Parental ethnicity, education, age, sex, marital status, and $\mathrm{BMI}$ and child age and sex
Main findings

Authoritative feeding styles were associated with higher levels of nurturance and organisation (general parenting) and monitoring of snack and high-fat food consumption (feeding practices). Authoritarian feeding styles were associated with higher levels of physical punishment (general parenting) and restriction and pressure to eat (feeding practices). Indulgent feeding styles were associated with lower levels of physical punishment (general parenting) and restriction and pressure to eat (feeding practices). Uninvolved feeding styles were associated with lower levels of nurturance and follow-through on discipline (general parenting) and monitoring (feeding practices). Children with indulgent parents had higher BMI $z$-scores compared with children with authoritarian parents

Indulgent feeding styles were associated with higher child BMI after controlling for child temperament, parental affect and known correlates. Indulgent parents reported lower negative affect for themselves and lower negative affectivity for their children

Parents with indulgent feeding styles made fewer demands on their children to eat during dinner and showed lower levels of negative affect and intrusiveness and higher levels of emotional detachment. Hispanic boys with indulgent parents had higher BMI scores compared with Hispanic boys with parents in the other three feeding style categories

The majority of immigrant mothers were categorised into high-demanding/low-responsive (authoritarian) or low-demanding/high-responsive (indulgent) feeding styles. Mothers with higher stress scores were more likely to express high-demanding/low-responsive (indulgent) feeding styles. The low-demanding/high-responsive (indulgent) feeding style was positively associated with child weight after adjusting for known correlates

The relationship between parenting style and feeding style showed modest agreement. Feeding style, but not parenting style, was associated with child BMI after controlling for known covariates (the indulgent feeding style was associated with a higher child weight status). Multiple regression analysis demonstrated that feeding style moderated the association between restrictive feeding practices and child BMI $z$-scores. No moderating relationship was found between feeding style and the practices of pressure to eat or monitoring and child weight 

relationship: a new paradigm for childhood obesity

A distinct research path has emerged in the obesity literature associating general parenting styles with children's overweight status ${ }^{(59)}$. A general parenting style refers to the overall attitude and emotional climate that a parent creates with his or her child ${ }^{(60,61)}$. Parents are categorised into one of the four parenting styles based on dimensions of demand/control and response/nurturance: authoritative (high demand/ high response), characterised by parental involvement, nurturance and structure; authoritarian (high demand/low response), characterised by restrictive, punitive and powerassertive behaviours; permissive/indulgent (low demand/ high response), characterised by warmth and acceptance in conjunction with a lack of monitoring; uninvolved (low demand/low response), characterised by little control and involvement.

Rhee et al. ${ }^{(59)}$ found childhood obesity to be most prevalent in children with parents having an authoritarian general parenting style - a finding consistent with an earlier work on high parental control of children's food intake and eating self-regulation ${ }^{(62)}$. The permissive/indulgent general parenting style was also found to be associated with an increased risk of childhood obesity ${ }^{(59,63,64)}$. These findings suggest that both high control and low control in parenting are a risk factor for childhood obesity.

A small number of studies have examined the relationship between general parenting styles and children's eating behaviours. The uninvolved general parenting style (also referred to as the rejecting style) was found to be negatively associated with children's fruit and vegetable intake ${ }^{(65,66)}$, while the permissive general parenting style was found to be positively associated with it ${ }^{(66)}$. However, a positive association between the authoritative general parenting style and children's fruit and vegetable intake has been the most consistent in the literature ${ }^{(65,67-69)}$. The authoritative general parenting style was also found to be negatively associated with children's high-fat and/or high-sugar food intake ${ }^{(63,69,70)}$.

More recently, the concept of feeding styles has been introduced into the literature, which embeds how parents interact with their children around eating within the general parenting style framework. Similar to general parenting styles, a feeding style refers to the overall attitude and emotional climate that a parent creates with his or her child during eating episodes, which in turn affects the child's eating behaviour. This relationship is depicted in Fig. 1.

The Caregiver's Feeding Styles Questionnaire ${ }^{(71)}$ measures styles of feeding along two dimensions: parental demandingness and responsiveness regarding children's eating behaviour. Demandingness refers to the extent to which parents are demanding of their children in eating episodes, while responsiveness refers to the extent to which parents show sensitivity towards their children's needs in the eating context. Similar to general parenting styles, differences in the two dimensions result in four styles of parental feeding: authoritative (high demand/high response), characterised by reasonable nutritional demands and feeding structure, as 
Table 2. Relationships between maternal mental health and parental feeding behaviours

\begin{tabular}{|c|c|c|c|c|c|c|}
\hline Author(s) & Study design & Subjects & $\begin{array}{l}\text { Maternal mental } \\
\text { health assessment }\end{array}$ & $\begin{array}{l}\text { Parental feeding } \\
\text { behaviour } \\
\text { assessment }\end{array}$ & $\begin{array}{l}\text { Adjustment for } \\
\text { potential cofounders }\end{array}$ & Main findings \\
\hline $\begin{array}{l}\text { Blissett \& } \\
\text { Farrow }^{(201)}\end{array}$ & $\begin{array}{l}\text { Questionnaires, } \\
\text { longitudinal } \\
\text { study, UK }\end{array}$ & $\begin{array}{l}\text { Sixty-two mothers of } \\
\text { 2-year-old children } \\
\text { (female: } n 31 \text {; } \\
\text { male: } n 31 \text { ). Well- } \\
\text { educated, professional } \\
\text { and affluent mothers }\end{array}$ & $\begin{array}{l}\text { GSI and BSI } \\
\text { at } 6 \text { and } 12 \text { months }\end{array}$ & $\begin{array}{l}\text { CFQ at } 12 \text { and } \\
24 \text { months }\end{array}$ & $\begin{array}{l}\text { Maternal occupation, } \\
\text { infant weight, infant } \\
\text { sex, number of births } \\
\text { and maternal age }\end{array}$ & $\begin{array}{l}\text { Controlling feeding practices at } 1 \text { year } \\
\text { were predicted by greater experience } \\
\text { of maternal psychological distress at } \\
6 \text { months. Parental control over feeding } \\
\text { at } 2 \text { years was predicted by } \\
\text { feeding strategy at } 1 \text { year }\end{array}$ \\
\hline $\begin{array}{l}\text { Farrow \& } \\
\quad \text { Blissett }^{(58)}\end{array}$ & $\begin{array}{l}\text { Questionnaires } \\
\text { and mealtime } \\
\text { observations, UK }\end{array}$ & $\begin{array}{l}\text { Eighty-seven } \\
\text { mother-infant } \\
\text { dyads }\end{array}$ & $\begin{array}{l}\text { BSI during pregnancy } \\
\text { and at } 6 \text { and } \\
12 \text { months } \\
\text { post-partum }\end{array}$ & CFQ & $\begin{array}{l}\text { Breast-feeding } \\
\text { duration and infant } \\
\text { weight }\end{array}$ & $\begin{array}{l}\text { Anxious psychopathology was significantly } \\
\text { associated with restrictive feeding } \\
\text { practices at } 1 \text { year. Maternal depression } \\
\text { was not significantly associated with } \\
\text { controlling or restrictive feeding practices } \\
\text { at } 1 \text { year }\end{array}$ \\
\hline $\begin{array}{l}\text { Francis } \\
\quad \text { et al. }\end{array}$ & $\begin{array}{l}\text { Questionnaires, } \\
\text { 5-year longitudinal } \\
\text { study, USA }\end{array}$ & $\begin{array}{l}104 \text { overweight } \\
\text { and ninety-two } \\
\text { non-overweight } \\
\text { mothers and their } \\
5 \text {-year-old, non-Hispanic, } \\
\text { White daughters }\end{array}$ & $\begin{array}{l}\text { CES-D (note: maternal } \\
\text { depression was } \\
\text { included as one of } \\
\text { the covariates) }\end{array}$ & CFQ & $\begin{array}{l}\text { Family income, } \\
\text { maternal education } \\
\text { and general } \\
\text { parenting style }\end{array}$ & $\begin{array}{l}\text { Maternal depression was related to } \\
\text { pressure to eat, but not to maternal } \\
\text { restriction }\end{array}$ \\
\hline $\begin{array}{l}\text { Goulding } \\
\text { et al. }\end{array}$ & $\begin{array}{l}\text { Cross-sectional, } \\
\text { observational } \\
\text { study, USA }\end{array}$ & $\begin{array}{l}295 \text { low-income mothers } \\
\text { and their 4- to 8-year-old } \\
\text { children (female: } \\
n \text { 143; male: } \\
n \text { 152) recruited from } \\
\text { Head Start programs }\end{array}$ & CES-D & $\begin{array}{l}\text { CFQ and CFSQ, } \\
\text { semi-structured } \\
\text { narrative interviews } \\
\text { and videotaped } \\
\text { observations }\end{array}$ & $\begin{array}{l}\text { Child sex, food } \\
\text { fussiness, and } \\
\text { number of older } \\
\text { siblings and maternal } \\
\text { age, BMl, education, } \\
\text { race/ethnicity, single- } \\
\text { parent status, } \\
\text { perceived child weight, } \\
\text { and concern about } \\
\text { child weight }\end{array}$ & $\begin{array}{l}\text { Elevated depressive symptoms were } \\
\text { related to more pressuring of children } \\
\text { to eat and overall demandingness } \\
\text { during feeding. Maternal depression } \\
\text { was associated with lower maternal } \\
\text { authority in child feeding. Maternal } \\
\text { depressive symptoms were not } \\
\text { significantly related to self-reported } \\
\text { restriction in child feeding }\end{array}$ \\
\hline $\begin{array}{l}\text { Hurley } \\
\text { et al. }\end{array}$ & $\begin{array}{l}\text { Telephone survey, } \\
\text { statewide sample, } \\
\text { Special Supplemental } \\
\text { Nutrition Program for } \\
\text { Women, Infants, and } \\
\text { Children, USA }\end{array}$ & $\begin{array}{l}702 \text { mother }- \text { infant dyads } \\
\text { (age range }= \\
0-12 \text { months) }\end{array}$ & $\begin{array}{l}\text { PSS, PRIME-MD } \\
\text { (PHQ) and STAI }\end{array}$ & CFQ, FYB and IFQ & $\begin{array}{l}\text { Maternal age, education, } \\
\text { number of births, } \\
\text { marital status and } \\
\text { ethnicity and infant } \\
\text { age and weight }\end{array}$ & $\begin{array}{l}\text { Maternal stress was associated with } \\
\text { forceful and uninvolved feeding; } \\
\text { maternal depression was associated } \\
\text { with forceful, indulgent and uninvolved } \\
\text { feeding; maternal anxiety was } \\
\text { associated with restrictive, forceful and } \\
\text { uninvolved feeding }\end{array}$ \\
\hline $\begin{array}{l}\text { Lumeng } \\
\text { et al. }\end{array}$ & $\begin{array}{l}\text { Questionnaires and } \\
\text { observations, Eunice } \\
\text { Kennedy Shriver } \\
\text { NICHD SECCYD } \\
\text { dataset, national } \\
\text { sample, USA }\end{array}$ & $\begin{array}{l}1218 \text { mothers and } \\
\text { their children (female: } \\
n 609 ; \text { male: } n 609 \text { ) }\end{array}$ & $\begin{array}{l}\text { CES-D (note: maternal } \\
\text { depression was } \\
\text { included as one of } \\
\text { the covariates) }\end{array}$ & $\begin{array}{l}\text { Videotaped feeding } \\
\text { interactions at } 15, \\
24 \text { and } 36 \text { months }\end{array}$ & $\begin{array}{l}\text { Child race/ethnicity } \\
\text { and sex, family } \\
\text { income:need ratio, } \\
\text { and maternal } \\
\text { education and } \\
\text { weight status }\end{array}$ & $\begin{array}{l}\text { Maternal depressive symptoms were } \\
\text { not associated with any maternal } \\
\text { feeding behaviour at any age }\end{array}$ \\
\hline $\begin{array}{l}\text { Mitchell } \\
\text { et al. }{ }^{89)}\end{array}$ & $\begin{array}{l}\text { Questionnaires, } \\
\text { Australia }\end{array}$ & $\begin{array}{l}124 \text { mothers and their } \\
\text { children (female: } n 65 ; \\
\text { male: } n \text { 59; mean } \\
\text { age }=6 \text { years) }\end{array}$ & DASS-21 & $\mathrm{CFQ}$ and $\mathrm{CFSQ}$ & & $\begin{array}{l}\text { Controlling feeding practices (restriction } \\
\text { and pressure to eat) and authoritarian } \\
\text { feeding styles were positively correlated } \\
\text { with maternal depression, anxiety and } \\
\text { stress }\end{array}$ \\
\hline
\end{tabular}


well as sensitivity towards the child's needs; authoritarian (high demand/low response), characterised by controlling feeding practices with little sensitivity towards the child's needs; indulgent (low demand/high response), characterised by a lack of rules and structure regarding feeding allowing the child the freedom to determine his or her nutritional intake; uninvolved (low demand/low response), characterised by a lack of control and involvement in feeding.

We searched a variety of databases for empirical studies on the relationship between maternal mental health and/or parent-child feeding behaviours and/or children's eating behaviours and/or children's weight status using the following search strategy: (maternal depression and/or life stress and/or maternal stress) and ('parenting styles' and/or 'feeding practices' and/or 'feeding styles' and/or 'authoritarian' and/or 'authoritative' and/or 'indulgent'). Most of the studies found evaluated additional variables such as infant temperament, maternal demographics and breast-feeding behaviour. However, for the purposes of this narrative review, the information was divided into two tables, specifically focusing on the relationships between parental feeding styles and children's eating behaviours and weight status (Table 1) and the relationships between maternal mental health and parental feeding styles (Table 2). For both reviews, the information tabulated includes the following: authors and year of publication; study design; subject characteristics; maternal mental health assessment used; parent-child feeding behaviour assessment used; variables used for adjustment; main findings (from the fully adjusted models).

A number of studies across the child nutrition literature have reported findings linking parental feeding styles and children's eating behaviours and weight status (Table 1). Across a series of studies involving African American, White and Hispanic low-income families with children aged 3-11 years, the indulgent feeding style was found to be associated with higher weight status in children $^{(71-75)}$. Furthermore, the indulgent feeding style was found to be associated with self-selected portion sizes and intake in children aged $4-6$ years ${ }^{(76)}$, a lower intake of fruits, vegetables and dairy foods in low-income preschoolers ${ }^{(77)}$, and a higher intake of low-nutrient, energy-dense snacks in rural lowincome ethnically diverse children ${ }^{(78)}$. The uninvolved feeding style was also found to be associated with a higher intake of energy-dense foods in preschoolers ${ }^{(77)}$. Conversely, the authoritative feeding style was found to be associated with a lower intake of low-nutrient, energy-dense snacks in children ${ }^{(78)}$. Details regarding the methods and specific results from these eight studies showing associations between indulgent feeding and children's eating behaviours/weight status are given in Table 1. In general, these studies support the theory that parents who are highly responsive to their children during eating episodes but do not set appropriate boundaries around food deter the development of appropriate eating behaviours that may contribute to children's weight gain.

Racial/ethnic differences have been observed across feeding styles. With regard to the two permissive feeding styles, Hispanic parents were found to more likely be indulgent, whereas African American parents were found to more likely be uninvolved ${ }^{(71)}$. 
In a separate study conducted among immigrant mother-child dyads of Brazilian, Haitian or Latino descent living in the Greater Boston area, the majority of the mothers were categorised as having an authoritarian feeding style or an indulgent feeding style $^{(75)}$. Moreover, among these immigrant mothers, women with higher stress scores were found to more likely express an authoritarian feeding style. More details regarding these studies are given in Table 1.

Distinct from parenting/feeding styles, feeding practices are considered more goal-oriented approaches to feeding where parents have specific aims regarding how and what they feed their children. There has been some confusion in the feeding literature regarding definitions of feeding constructs and the use of the terms styles, practices, strategies and directives to depict parent-child feeding behaviours ${ }^{(79)}$. The aforementioned definitions of parenting styles, feeding styles and feeding practices will be used for the purposes of this review paper. Parent-child feeding behaviours will encompass both feeding style and feeding practice constructs.

Certain feeding practices have been shown to be detrimental to the development of appropriate eating behaviours in children. These include prompts to eat ${ }^{(80)}$, restriction on eating certain foods ${ }^{(81)}$, using food as a reward ${ }^{(81)}$ and some types of modelling ${ }^{(80)}$. The use of these practices can lead to negative consequences for children. Parents who continually prompt their children to eat during eating episodes divert attention away from their internal cues of fullness, which may cause problems with eating self-regulation ${ }^{(80)}$. When food is used as a reward (e.g. getting dessert for eating vegetables), the reward becomes the desirable object, while the required food becomes less desirable ${ }^{(82)}$. In the long term, this could lead to a shift in neurophysiology that would sensitise the brain's mesolimbic dopamine system to crave greater quantities of the reward ${ }^{(83,84)}$. Although modelling has been shown to have positive associations with children's intake ${ }^{(85)}$, parents can unintentionally model unhealthy behaviours (consuming large portions or eating high-fat foods) without realising the consequences for their children. Finally, restrictive feeding practices have been shown to be counterproductive such that restricted foods become sought after by the child when the food becomes available and the parent is no longer there to restrict ${ }^{(80,81)}$.

Most studies examining restriction, use of rewards and modelling have been based on parents' report of their own behaviour. Many of the studies examining these constructs have done so without considering the context of their use. For example, restriction has been linked to children's behaviours in predominantly experimental studies in laboratory settings. Furthermore, in a recent study of parent-child interactions using direct observation, the use of rewards as a feeding practice was almost non-existent ${ }^{(86)}$. Moreover, the use of eating prompts was the most common and consistent feeding practice observed in parent-child interactions during meals ${ }^{(86)}$. More work is needed to determine whether restriction, use of rewards and modelling (highly studied individual feeding practice constructs) are commonly used in the home environment during parent-child eating episodes.
The Child Feeding Questionnaire is the most common instrument used in the childhood obesity literature to measure parental feeding practices ${ }^{(87)}$. This questionnaire measures three feeding practice constructs: restriction (the extent to which parents limit their children's access to 'unhealthy' foods); pressure to eat (the degree to which parents attempt to make sure that their children are eating enough); monitoring (the extent to which parents keep track of their children's snack and high-fat food intake). Restriction and pressure to eat are the only two feeding practice constructs that have consistently been found to be associated with children's weight status over multiple studies ${ }^{(47,88)}$.

\section{Maternal depression, parenting styles, and feeding styles and practices}

Research regarding general parenting indicates that low levels of parental satisfaction are associated with more-controlling and less-responsive parenting styles and practices ${ }^{(89-91)}$. Maternal depression can impair parenting practices and has been linked to less-sensitive feeding interactions with children, but existing research is based on self-reports of feeding practices. Haycraft et al. ${ }^{(92)}$ examined the relationships between maternal self-reported symptoms of depression and observations of mothers' feeding practices during a meal occasion. Mothers who reported greater symptoms of depression were found to use more verbal and physical pressure for their children to eat and to offer more incentives or conditions in exchange for their children eating. Mothers also used more vocalisations with their children about food during the observed meal occasion when they had greater symptoms of depression. There was no link between symptoms of depression and observations of maternal use of restriction. Symptoms of depression were found to be linked to observations of mothers implementing more-controlling, less-sensitive feeding practices with their children ${ }^{(92)}$. Moreover, Hughes et al. ${ }^{(71)}$ found higher levels of general parental control and authoritarian feeding practices (i.e. pressuring children to eat more food and restricting them from eating certain amounts or types of foods) to be associated with authoritarian feeding styles. In contrast, higher levels of general parenting responsiveness were found to be associated with authoritative feeding styles. The influence of maternal depression over parental feeding styles, and consequently over childhood obesity, is depicted in Fig. 1.

\section{Maternal depression, stress and feeding behaviours}

In our search for articles examining maternal mental health and parental feeding behaviours, over thirty articles were reviewed; however, only eight articles were found to specifically address the relationship between maternal mental health and parental feeding. In particular, these eight studies included an assessment of maternal mental health. The major characteristics of these eight studies are summarised in Table 2 .

Most of the studies were conducted in either the USA or the UK, while one study was conducted in Australia. The majority 
of studies had a longitudinal design, and all of them used questionnaires as their main data collection tool. Subjects were mother-infant dyads, with numbers ranging from 62 to 702 per study. Most of the subjects were White, except for the participants of a study involving immigrant motherinfant dyads.

Maternal mental health variables were measured using a variety of instruments. Of the six studies that assessed maternal mental health, two used the Brief Symptom Inventory, while two other studies used the Center for Epidemiological Studies-Depression Scale. The other questionnaires used included the Global Severity Index, the Perceived Stress Scale, the Primary Care Evaluation of Mental Disorders Patient Health Questionnaire, the Spielberger State-Trait Anxiety Inventory, and the Depression Anxiety and Stress Scale.

Parent-child feeding behaviours were assessed using a variety of questionnaires. Of the six studies that assessed parent-child feeding behaviours, five used the Child Feeding Questionnaire. The sixth study used the Caregiver's Feeding Styles Questionnaire - also used in other studies. Other questionnaires used were the Infant Feeding Questionnaire and Feeding Your Baby.

Finally, most of the studies adjusted for a wide range of potential confounding factors. Most, but not all, of the studies adjusted for well-known factors associated with depression such as breast-feeding duration, infant weight, and socioeconomic factors such as education and income.

\section{Maternal depression, stress and eating behaviours}

Eating is often cited as a means of coping with stress ${ }^{(93,94)}$. Stress affects eating behaviours in different people in different ways. Studies have demonstrated both increased (hyperphagic response) and decreased (hypophagic response) eating in response to stress ${ }^{(95)}$. Greeno \& Wing ${ }^{(96)}$ concluded that chronic stressors tend to facilitate hypophagia, whereas acute and possibly milder stressors often result in hyperphagia. Greater stress was also found to be associated with more fatty food intake, less fruit and vegetable intake, more snacking, and a reduced likelihood of daily breakfast consumption ${ }^{(97)}$. These effects were independent of individual (sex and weight) and social (SES and ethnicity) factors. Nonetheless, some investigators are beginning to establish a link between chronic stress and overeating (especially high-fat, high-carbohydrate and comfort foods) within the African American community ${ }^{(98)}$. Increased intake of snack-type foods and decreased intake of meal-type foods were found to occur with increased stress ${ }^{(99)}$. Stress was found to be associated with higher energy and saturated fat and sugar intakes ${ }^{(100)}$. A significant moderating effect of restrained eating, with a hyperphagic response to stress, was observed in restrained eaters, compared with no effect in unrestrained eaters ${ }^{(100)}$. In contrast, another study demonstrated that females with high scores on disinhibition significantly ate more during stress and that neither disinhibition nor restraint was associated with the relationship between eating and stress in males ${ }^{(101)}$. Clearly, stress is related to eating. There is a growing body of research linking dysregulated stress physiology to an increased vulnerability to reward (i.e. dopamine)-producing behaviours (i.e. eating and drug use $)^{(83,84,102-104)}$. We theorise that chronic exposure to stress will have a direct impact on eating behaviours and feeding styles. However, more research is needed to clarify the stress-eating association, particularly in various ethnic populations. Similar to stress, depression is associated with changes in an individual's eating behaviour. One of the diagnostic criteria for major depression is the change in eating behaviour ${ }^{(105)}$. The relationship between maternal depression and stress and their association with mother's own eating behaviour are depicted in Fig. 1. Moreover, preliminary investigations suggest that prenatal and postnatal depressive symptomatology experienced by the mother - along with SES - could also have a deleterious effect on her child's stress regulatory systems ${ }^{(106-108)}$

\section{Resemblance of mother and child food consumption patterns}

Family dietary practices have been shown to be an important determinant of children's diet quality. Parents are gatekeepers and can serve as role models for their children's health-related behaviours ${ }^{(80,85,109-112)}$, including diet. Parental food preferences $^{(113)}$ and dietary intake ${ }^{(85,114-116)}$ have been shown to influence children's eating behaviours (see Fig. 1). The majority of studies have documented the impact of maternal influences on the dietary intake of young children.

Young children imitate their parents in their choice of $\operatorname{diets}^{(85,110,116)}$; for example, preschool children have been shown to choose healthy foods that they have seen their parents purchase $^{(117,118)}$. A strong positive correlation was found between the dietary intake of younger children and that of their parents than between the dietary intake of older children or adolescents and that of their parents ${ }^{(85)}$. Stronger positive correlations have been shown between the dietary intake of parents and that of their daughters ${ }^{(85,119)}$ than between the dietary intake of parents and that of their sons ${ }^{(85,115)}$. Although there is a widespread perception of a strong resemblance in parent-child dietary intakes $^{(120-123)}$, surprisingly, some studies have shown that the resemblance is weak ${ }^{(85)}$. This is probably because the eating patterns of children are influenced by a variety of factors ${ }^{(111)}$, and the family environment is just one of these factors.

Evidence suggests correlations between nutrient intakes among family members ${ }^{(115,124)}$. More recently, studies have focused on familial resemblance in dietary intake patterns, such as consumption of dairy products ${ }^{(115,125,126)}$, sweetened beverages $^{(115,126)}$, fruits and vegetables ${ }^{(112,115,124)}$, and snacks/sweets ${ }^{(112,115)}$. Parent-child dietary intake resemblance was found to vary by food group ${ }^{(115)}$. This is not surprising given that the majority of studies evaluated single foods or food groups in isolation and not within the context of a meal. A recent study has expanded the current literature to include an examination of resemblance in intakes of foods, within the context of a meal, among mother-child dyads from families of limited incomes ${ }^{(127)}$. Moderate-tostrong correlations were observed between the intakes of foods consumed at the dinner meal occasion among the mother-child dyads. The foods/beverages that the mothers 
served themselves were a significant predictor of the type and amounts of foods that their children were served.

\section{Children's eating behaviours and obesity}

Differing eating patterns confound our understanding of the relationship between nutrient intake and chronic diseases, including obesity ${ }^{(128)}$. Eating patterns include restaurant food consumption, beverage consumption, portion sizes, meal patterns and meal frequency, school meal participation and consumption, and diet quality. The link between children's eating behaviours and obesity is depicted in Fig. 1. Some studies have reported each of these eating pattern components and its relationship with child nutrition.

The estimated frequency of fast-food meal consumption was found to be positively associated with energy intake in women $^{(129)}$. Daily energy intake away from home has increased from $23 \%$ (1977) to $34 \%(2006)^{(130)}$. Fast foods were the largest contributor of foods prepared away from home providing 3.5\% of energy intake in 1994 and $6.1 \%$ in 2006 in children ${ }^{(130)}$. Children consuming fast foods were found to have higher intakes of energy, total fat, SFA and sugar than those who did not ${ }^{(131,132)}$. Thus, fast food consumption was found to have a negative impact on diet quality $^{(133)}$. Fast food restaurants contribute few servings of fruits, vegetables, whole grains and dairy foods to the diets of children ${ }^{(132,134,135)}$. The frequency of restaurant food consumption was found to be positively associated with increased body fatness in adults ${ }^{(136)}$. Obese individuals were found to choose more total food at a fast food restaurant than their leaner counterparts, but this did not occur at the other types of eating establishments studied ${ }^{(137)}$. The increasing proportion of household food income spent on foods prepared away from home may help to explain the rising national prevalence of obesity.

The possible relationship between sugar-sweetened beverage consumption and obesity received a lot of attention when a 2001 prospective study reported that the consumption of sugar-sweetened beverages is associated with a $60 \%$ increase in the risk of obesity in 11-12-year-old children ${ }^{(138)}$. Although this study ignited a controversial debate, several criticisms have been raised on the interpretation of the study's findings ${ }^{(139-141)}$. From 2006 to 2007, four review articles have been published ${ }^{(142-145)}$ : two of the articles stated that there is strong evidence that sweetened beverage consumption is associated with weight status ${ }^{(142,143)}$; however, the other two articles concluded that the evidence is inconclusive ${ }^{(144,145)}$. Another ten review articles have been published from 2007 to $2010^{(146-155)}$. Once again, there was no consensus regarding the evidence: five articles concluded that the evidence on the relationship between sugar-sweetened beverage consumption and weight is inconclusive $\mathrm{i}^{(146-150)}$ and the other four articles stated that the evidence is strong ${ }^{(151,152,154,155)}$. There are several reasons for the discrepancies found in studies investigating the association between sugar-sweetened beverage consumption and weight status ${ }^{(146)}$. However, the verdict is not yet out that sugar-sweetened beverage consumption is a major eating pattern associated with obesity. As with any food, if one eats too much, it will contribute energy to the diet and will cause weight gain if energy intake exceeds energy expenditure.

Only a few studies have examined the influence of portion size on intake in adults ${ }^{(156-159)}$ and children ${ }^{(160)}$. Adults were found to consume more food when served portions that were 1.5 times larger than a standard portion size ${ }^{(161,162)}$. Larger portion sizes have been shown to increase the intakes of both lean and obese adults ${ }^{(156)}$. Similarly, 5-year-old children were found to consume greater amounts when presented with larger portions ${ }^{(160)}$. Several studies have shown that providing children with larger food portions leads to significant increases in food and energy intakes ${ }^{(163)}$. Children aged 3-5 years were found to consume more of the entrée and less of the other foods, such as fruits and vegetables, when larger entrée portions were served, resulting in an increased energy intake ${ }^{(163)}$. Larger portion sizes could be contributing to the increasing prevalence of overweight among children and young adults ${ }^{(164)}$.

Adolescents with a consistent meal pattern (i.e. three meals a day) were found to be leaner than those with an inconsistent meal pattern ${ }^{(165)}$. This observation is in agreement with findings from studies showing a link between obesity and skipping meals ${ }^{(165-169)}$. An inconsistent meal pattern may mean skipping meals to reduce energy.

Breakfast consumption has been shown to improve nutrient intake ${ }^{(170-173)}$ and to be associated with lower BMI and other measures of adiposity in children ${ }^{(170,172-178)}$. Ready-to-eat cereals $^{(172,179-181)}$, including pre-sweetened ready-to-eat cereal $^{(182,183)}$ breakfasts, have specifically been shown to be associated with lower measures of weight and adiposity. In one study ${ }^{(172)}$, weight/adiposity parameters of individuals consuming 'other breakfasts' were compared with those of breakfast skippers and those consuming ready-to-eat cereal breakfasts and BMI $z$-scores and waist circumferences of the breakfast skippers were found to be greater than those of individuals consuming ready-to-eat cereals or 'other breakfasts'. A recent systematic review and meta-analysis ${ }^{(184)}$ has concluded that evidence that regular consumption of breakfast cereals results in a lower BMI and a reduced likelihood of being overweight in children and adolescents is suggestive. However, a cumulative meta-analysis challenges the proposition that skipping breakfast leads to weight gain ${ }^{(185)}$. It is concluded that the scientific evidence is distorted by research lacking probative value and biased research reporting. More long-term trials are needed to better understand the proposed effect of breakfast consumption on obesity and potential mechanisms.

The percentage of children consuming snacks has increased from $74 \%$ in $1977-78$ to $98 \%$ in $2003-6^{(186)}$. Snacks have been shown to be associated with an increased energy intake, accounting for more than $27 \%$ of daily energy intake in children $^{(186,187)}$. In addition, snacking contributes significantly to nutrient intake ${ }^{(187-189)}$. The relationship between snacking and childhood obesity is less clear. Nearly 15 years ago, the Booth hypothesis ${ }^{(190)}$ has stated that 'grazing' or multiple eating episodes between meals, rather than the traditional 
pattern of three meals per $\mathrm{d}$, is a major contributing factor of obesity. Conversely, few studies have actually shown that snacking is negatively associated with body fatness ${ }^{(191)}$ and a reduced risk of overweight and abdominal obesity ${ }^{(192,193)}$. However, other studies have shown that snacking is not associated with weight status ${ }^{(187,194)}$ and not an independent predictor of weight gain ${ }^{(195)}$. There are several possible explanations for the inconsistent results on the association between snacking and childhood obesity. Study results may be equivocal because snack definitions have not been clearly established or are inconsistent across studies ${ }^{(186,196-198)}$. Moreover, snacking patterns are not homogeneous and vary considerably in their contribution to dietary intake ${ }^{(199,200)}$.

\section{Adaptation of the extended UNICEF care model}

The aim of the present narrative review paper was to extend the UNICEF care model to focus on childhood obesity and its associated risks with an emphasis on the emotional climate of the parent-child relationship within the family (see Fig. 1). We sought to integrate previously unintegrated sets of literature across multiple disciplines including developmental psychology, clinical psychology and nutrition. In doing so, we discussed empirical evidence in support of the following links highlighted in Fig. 1: the relationships between maternal mental health (specifically depression) and parental feeding; the relationships between parental feeding styles and children's eating behaviours and weight status; the relationships between maternal stress and depression and mother's own eating behaviour; resemblance in mother-child food consumption patterns. Together, the studies reviewed herein point to the importance of considering the emotional climate of the parent-child relationship within the family in a systems approach to obesity.

\section{Limitations and future research directions}

Our narrative review revealed several limitations in the research designed to further espouse the links previously reviewed and integrated to the adaptation of the extended UNICEF care model. First, there remain clear gaps in the literature in terms of the number of studies that include maternal mental health in the emotional climate of the parent-child feeding relationship, with only six studies identified linking maternal mental health to feeding. Importantly, future studies should include measurement of main effects as demonstrated in Fig. 1 in combination with consideration of moderating and mediating effects, as there is a significant dearth of studies that test the full model. The use of structural equation modelling in this regard with large prospective sampling designs will be important to move the field forward. Second, current research is characterised by several methodological limitations such as an overreliance on self-reports as well as questionnaire-based measures. The impact of future studies may be greatly affected by the inclusion of interview-based measures of depression and stress in mothers and observational measures of feeding within the context of the family. Third, it became clear to us in conducting this narrative review that there is a serious lack of cross talk between psychology and nutrition with the direction of a lack of cross talk potentially being in the direction of a lack of integration of nutrition work in clinical psychology. No standard handbook on depression includes a section or chapter on the effects of maternal depression on children's overweight status or parent-child feeding behaviours in the household. There is a clear gap in communication that may be addressed by reviews of the current sort being published in clinical psychology and psychiatry journals. Finally, the potential effect of cultural worldviews, beliefs and practices on coping with stress and eating styles is yet to be studied with adequate specificity. Being able to effectively measure culture-specific constructs will allow for empirically driven interpretations of within-group and between-group differences.

\section{Conclusion}

Notwithstanding the limitations described above, our extension of the UNICEF model provides a roadmap for future research to stimulate cross-disciplinary research into the complex problem of obesity. It is only through a complex understanding of the aetiology of a problem that factors may be identified for targeted and effective intervention.

\section{Acknowledgements}

The authors cordially thank Lori Briones for helping with the preparation of the manuscript and Bee Wong for obtaining research articles.

This research project was supported in part by the USDAAgricultural Research Service through specific cooperative agreement 58-6250-6-003.

The authors' contributions are as follows: T. A. N. conceptualised the research and A. F. E.-B. wrote the first draft of the manuscript; C. S., E. M. O. and S. O. H. substantially revised the manuscript with critical feedback.

Authorship responsibility: All the authors listed herein meet the criteria set by the International Committee of Medical Journal Editors. No one who might consider that he or she has a right to be an author has been excluded. Ethics Committee: Institutional Review Board for Baylor College of Medicine and Affiliated Hospitals.

The authors declare that they have no conflicts regarding this work and have no involvements that might raise the question of bias in the work reported or in the conclusions, implications and opinions stated.

\section{References}

1. Ogden CL, Carroll MD, Kit BK, et al. (2012) Prevalence of obesity and trends in body mass index among US children and adolescents, 1999-2010. JAMA 307, 483-490.

2. Webber L, Cresanta J, Croft J, et al. (1986) Transitions of cardiovascular risk from adolescence to young adulthoodthe Bogalusa Heart Study: II. Alterations in anthropometric blood pressure and serum lipoprotein variables. J Chronic Dis 39, 91-103. 
3. Serdula MK, Ivery D, Coates RJ, et al. (1993) Do obese children become obese adults? A review of the literature. Prev Med 22, 167-177.

4. Guo SS, Roche AF, Chumlea WC, et al. (1994) The predictive value of childhood body mass index values for overweight at age 35 y. Am J Clin Nutr 59, 810-819.

5. Calle EE, Rodriguez C, Walker-Thurmond K, et al. (2003) Overweight, obesity, and mortality from cancer in a prospectively studied cohort of U.S. adults. $N$ Engl J Med 348, 1625-1638.

6. Shike M (1996) Body weight and colon cancer. Am J Clin Nutr 63, 442S-444S.

7. Murphy TK, Calle EE, Rodriguez C, et al. (2000) Body mass index and colon cancer mortality in a large prospective study. Am J Epidemiol 152, 847-854.

8. Bungum T, Satterwhite M, Jackson AW, et al. (2003) The relationship of body mass index, medical costs, and job absenteeism. Am J Health Behav 27, 456-462.

9. Fontaine KR, Redden DT, Wang C, et al. (2003) Years of life lost due to obesity. JAMA 289, 187-193.

10. Ford ES, Moriarty DG, Zack MM, et al. (2001) Self-reported body mass index and health-related quality of life: findings from the Behavioral Risk Factor Surveillance System. Obes Res 9, 21-31.

11. Sturm R, Ringel JS \& Andreyeva T (2004) Increasing obesity rates and disability trends. Health Aff (Millwood) 23, 199-205.

12. Burton WN, Chen CY, Schultz AB, et al. (1999) The costs of body mass index levels in an employed population. Stat Bull Metrop Insur Co 80, 8-14.

13. Cawley J \& Meyerhoefer C (2012) The medical care costs of obesity: an instrumental variables approach. $J$ Health Econ 31, 219-230.

14. Mei Z, Scanlon KS, Grummer-Strawn LM, et al. (1998) Increasing prevalence of overweight among US lowincome preschool children: the Centers for Disease Control and Prevention pediatric nutrition surveillance, 1983 to 1995. Pediatrics 101, E12.

15. Mokdad AH, Serdula MK, Dietz WH, et al. (2000) The continuing epidemic of obesity in the United States. JAMA 284, 1650-1651.

16. Ogden C, Flegal K, Carroll M, et al. (2002) Prevalence and trends in overweight among US children and adolescents, 1999-2000. JAMA 149, 1085-1091.

17. Flegal KM, Carroll MD, Kit BK, et al. (2012) Prevalence of obesity and trends in the distribution of body mass index among US adults, 1999-2010. JAMA 307, 491-497.

18. Engle PL, Menon P, Garrett JL, et al. (1997) Urbanization and caregiving: a framework for analysis and examples from southern and eastern Africa. Environ Urban 9, $253-270$

19. Wachs TD (2008) Multiple influences on children's nutritional deficiencies: a systems perspective. Physiol Behav 94, 48-60.

20. Wachs T \& McCabe G (2001) Relation of maternal intelligence and schooling to offspring nutritional intake. Int $J$ Behav Dev 25, 444-449.

21. Oropesa R \& Landale N (1997) Immigrant legacies: ethnicity, generation, and children's familial and economic lives. Soc Sci Quart 78, 399-416.

22. Boyle M, Racine Y, Georgiades K, et al. (2006) The influence of economic development level, household wealth and maternal education on child health in the developing world. Soc Sci Med 63, 2242-2254.

23. Pongou R, Salomon J \& Ezzati M (2006) Health impacts of macroeconomic crises and policies: determinants of variation in childhood malnutrition trends in Cameroon. Int J Epidemiol 35, 648-656.

24. Winkvist A (1995) Health and nutrition status of the caregiver: effect on caregiving capacity. Food Nutr Bull 16, 389-397.

25. Baughcum AE, Chamberlin LA, Deeks CM, et al. (2000) Maternal perceptions of overweight preschool children. Pediatrics 106, 1380-1386.

26. Jiang J, Rosenqvist U, Wang $\mathrm{H}$, et al. (2006) Risk factors for overweight in 2- to 6-year-old children in Beijing, China. Int J Pediatr Obes 1, 103-108.

27. Strauss RS \& Knight J (1999) Influence of the home environment on the development of obesity in children. Pediatrics 103, e85.

28. Lumeng JC \& Burke LM (2006) Maternal prompts to eat, child compliance, and mother and child weight status. J Pediatr 149, 330-335.

29. Genovesi S, Giussani M, Faini A, et al. (2005) Maternal perception of excess weight in children: a survey conducted by paediatricians in the province of Milan. Acta Paediatr 94, 747-752.

30. Padez C, Mourao I, Moreira P, et al. (2005) Prevalence and risk factors for overweight and obesity in Portuguese children. Acta Paediatr 94, 1550-1557.

31. Patterson ML, Stern S, Crawford PB, et al. (1997) Sociodemographic factors and obesity in preadolescent black and white girls: NHLBI's Growth and Health Study. J Natl Med Assoc 89, 594-600.

32. Martorell R, Khan LK, Hughes ML, et al. (1998) Obesity in Latin American women and children. J Nutr 128, $1464-1473$.

33. Kushi LH, Folsom AR, Jacobs DR, et al. (1988) Educational attainment and nutrient consumption patterns: the Minnesota Heart Survey. J Am Diet Assoc 88, 1230-1236.

34. Van Horn L, Ballew C, Liu K, et al. (1991) Diet, body size, and plasma lipids-lipoproteins in young adults: differences by race ad sex: the Coronary Artery Risk Development in Young Adults (CARDIA) study. Am J Epidemiol 133, 9-23.

35. Jacobsen BK \& Thelle DS (1988) Risk factors for coronary heart disease and level of education: The Tromso Heart Study. Am J Epidemiol 127, 923-932.

36. Whitaker RC, Wright JA, Koepsell TD, et al. (1994) Characteristics of children selecting low-fat foods in an elementary school lunch program. Arch Pediatr Adolesc Med 148, 1085-1091.

37. Rahman A, Harrington R \& Bunn J (2002) Can maternal depression increase infant risk of illness and growth impairment in developing countries? Child Care Health Dev 28, $51-56$.

38. Engle P \& Zeitlin M (1996) Active feeding behavior compensates for low interest in food among young Nicaraguan children. Nutrition 126, 1808-1816.

39. Hostetter A \& Stowe Z (2002) Postpartum mood disorders: identification and treatment. In Psychiatric Illness in Women: Emerging Treatments and Research, pp. 133-156 [F Lewis-Hall, TS Williams, JA Panetta and JM Herrera, editors]. Washington, DC: American Psychiatric Publishing, Inc.

40. Francis LA, Hofer SM \& Birch LL (2001) Predictors of maternal child-feeding style: maternal and child characteristics. Appetite 37, 231-243.

41. Stice E, Shaw H \& Marti C (2006) A meta-analytic review of obesity prevention programs for children and adolescents: the skinny on interventions that work. Psychol Bull 132, 667-691. 
42. Haynos A \& O'Donohue W (2012) Universal childhood and adolescent obesity prevention programs: review and critical analysis. Clin Psychol Rev 32, 383-399.

43. Teixeira E (2011) The effectiveness of community-based programs for obesity prevention and control. Patient Intelligence 3, 63-72.

44. Summerbell CD, Waters E, Edmunds LD, et al. (2005) Interventions for preventing obesity in children. The Cochrane Database of Systematic Reviews 2005, issue 3, CD001871.

45. Mitchell GL, Farrow C, Haycraft E, et al. (2013) Parental influences on children's eating behaviour and characteristics of successful parent-focussed interventions. Appetite 60, 85-94.

46. Birch L \& Davison K (2001) Family environmental factors influencing the developing behavioral controls of food intake and childhood overweight. Pediatr Clin North Am 48, 893-907.

47. Faith MS, Scanlon KS, Birch LL, et al. (2004) Parent-child feeding strategies and their relationships to child eating and weight status. Obes Res 12, 1711-1722.

48. Brody GH \& Flor DL (1997) Maternal psychological functioning, family processes, and child adjustment in rural, single-parent, African American families. Dev Psychol 33, 1000-1011.

49. Hall LA, Williams CA \& Greenberg RS (1985) Supports, stressors, and depressive symptoms in low-income mothers of young children. Am J Public Health 75, 518-522.

50. Orr ST, James SA, Burns BJ, et al. (1989) Chronic stressors and maternal depression: implications for prevention. Am J Public Health 79, 1295-1296.

51. Heneghan AM, Silver EJ, Bauman LJ, et al. (1998) Depressive symptoms in inner-city mothers of young children: who is at risk? Pediatrics 102, 1394-1400.

52. Chung EK, McCollum KF, Elo IT, et al. (2004) Maternal depressive symptoms and infant health practices among low-income women. Pediatrics 113, e523-e529.

53. Zuckerman BS \& Beardslee WR (1987) Maternal depression: a concern for pediatricians. Pediatrics 79, 110-117.

54. Hopkins J, Marcus M \& Campbell SB (1984) Postpartum depression: a critical review. Psychol Bull 95, 498-515.

55. Sachs B, Hall LA \& Pietrukowicz MA (1995) Moving beyond survival: coping behaviours of low-income single mothers. J Psychiatr Ment Health Nurs 2, 207-215.

56. Sack WH, Mason R \& Higgins JE (1985) The single-parent family and abusive child punishment. Am J Orthopsychiatry 55, 252-259.

57. Susman EJ, Trickett PK, Iannotti RJ, et al. (1985) Childrearing patterns in depressed, abusive, and normal mothers. Am J Orthopsychiatry 55, 237-251.

58. Farrow CV \& Blissett JM (2005) Is maternal psychopathology related to obesigenic feeding practices at 1 year? Obes Res 13, 1999-2005.

59. Rhee KE, Lumeng JC, Appugliese DP, et al. (2006) Parenting styles and overweight status in first grade. Pediatrics 117, 2047-2054.

60. Baumrind D (1989) Rearing competent children. In Child Development Today and Tomorrow, pp. 349-378 [W Damon, editor]. San Francisco, CA: Jossey Bass.

61. Maccoby E \& Martin J (1983) Socialization in the context of the family: parent-child interaction. In Handbook of Child Psychology, pp. 100-101 [PH Mussen, editor]. New York, NY: Wiley.

62. Birch LL, Fisher JO \& Davison KK (2003) Learning to overeat: maternal use of restrictive feeding practices promotes girls' eating in the absence of hunger. Am J Clin Nutr $\mathbf{7 8}$ 215-220.

63. Chen JL \& Kennedy C (2005) Factors associated with obesity in Chinese-American children. Pediatr Nurs 31, $110-115$.

64. Wake M, Nicholson JM, Hardy P, et al. (2007) Preschooler obesity and parenting styles of mothers and fathers: Australian National Population Study. Pediatrics 120, e1520-e1527.

65. Rodenburg G, Oenema A, Kremers SP, et al. (2012) Parental and child fruit consumption in the context of general parenting, parental education and ethnic background. Appetite 58, 364-372.

66. Franchini B, Poinhos R, Klepp K, et al. (2011) Association between parenting styles and own fruit and vegetable consumption among Portuguese mothers of school children. Br J Nutr 106, 931-935.

67. Lytle LA, Varnell S, Murray DM, et al. (2003) Predicting adolescents' intake of fruits and vegetables. J Nutr Educ Behav 35, 170-175.

68. Park H \& Walton-Moss B (2012) Parenting style, parenting stress, and children's health-related behaviors. I Dev Behav Pediatr 33, 495-503.

69. Pearson N, Atkin A, Biddle S, et al. (2010) Parenting styles, family structure and adolescent dietary behaviour. Public Health Nutr 13, 1245-1253.

70. Van der Horst K, Kremers S, Ferreira I, et al. (2007) Perceived parenting style and practices and the consumption of sugar-sweetened beverages by adolescents. Health Educ Res 22, 295-304.

71. Hughes S, Power T, Orlet Fisher J, et al. (2005) Revisiting a neglected construct: parenting styles in a child-feeding context. Appetite 44, 83-92.

72. Hennessy E, Hughes S, Goldberg J, et al. (2010) Parent behavior and child weight status among a diverse group of underserved rural families. Appetite 54, 369-377.

73. Hughes S, Shewchuk R, Baskin M, et al. (2008) Indulgent feeding style and children's weight status in preschool. $J$ Dev Behav Pediatr 29, 403-410.

74. Hughes S, Power T, Papaioannou M, et al. (2011) Emotional climate, feeding practices, and feeding styles: an observational analysis of the dinner meal in Head Start families. Int J Behav Nutr Phys Act 8, 60.

75. Tovar A, Hennessy E, Pirie A, et al. (2012) Feeding styles and child weight status among recent immigrant motherchild dyads: a cross-sectional analysis. Int J Behav Nutr Phys Act 9, 62 .

76. Fisher J, Birch L, Zhang J, et al. (2013) External influences on children's self-served portions at meals. Int $J$ Obes (London) 37, 954-960.

77. Hoerr SL, Hughes SO, Fisher JO, et al. (2009) Associations among parental feeding styles and children's food intake in families with limited incomes. Int J Behav Nutr Phys Act 6, 55 .

78. Hennessy E, Hughes S, Goldberg J, et al. (2012) Permissive parental feeding behaviors is associated with an increase in intake of low nutrient-dense foods among American children living in rural communities. J Acad Nutr Diet 112, 142-148.

79. Hughes S, Frankel L, Beltran A, et al. (2013) Food parenting measurement issues: Working Group Consensus Report. Child Obes 9, S-95-S-102.

80. Savage J, Fisher J \& Birch L (2007) Parental influence on eating behavior: conception to adolescence. J Law Med Ethics 35, 22-34. 
81. Rhee K (2008) Childhood overweight and the relationship between parent behaviors, parenting style, and family functioning. Ann Am Acad Polit Soc Sci 615, 11-37.

82. Benton D (2004) Role of parents in the determination of the food preferences of children and the development of obesity. Int J Obes Relat Metab Disord 28, 858-869.

83. Al'Absi M (2006) Stress and Addiction: Biological and Psychological Mechanisms. San Diego, CA: Elsevier Academic Press. http://www.sciencedirect.com/science/ book/9780123706324 (accessed 28 August 2014).

84. Pani L, Porcella A \& Gessa GL (2000) The role of stress in the pathophysiology of the dopaminergic system. Mol Psychiatry 5, 14-27.

85. Wang Y, Beydoun M, Li J, et al. (2011) Do children and their parents eat a similar diet? Resemblance in child parent dietary intake; systematic review and meta-analysis. J Epidemiol Community Health 65, 177-189.

86. Power TG, Hughes SO, Goodell LS, et al. Feeding practices of low-income mothers: How do they compare to current recommendations? Int J Behav Nutr Phys Act (Under Review).

87. Birch LL, Fisher JO, Grimm-Thomas K, et al. (2001) Confirmatory factor analysis of the Child Feeding Questionnaire: a measure of parental attitudes, beliefs and practices about child feeding and obesity proneness. Appetite 36, 201-210.

88. Clark H, Goyder E, Bissell P, et al. (2007) How do parents' child-feeding behaviours influence child weight? Implications for childhood obesity policy. J Public Health (Oxf) 29, 132-141.

89. Mitchell S, Brennan L, Hayes L, et al. (2009) Maternal psychosocial predictors of controlling parental feeding styles and practices. Appetite 53, 384-389.

90. Ohan J, Leung D \& Johnston C (2000) The parenting sense of competence scale: evidence of a stable factor structure and validity. Can J Behav Sci 32, 251-261.

91. Simons R, Beaman J, Conger R, et al. (1993) Stress, support, and antisocial behavior trait as determinants of emotional well-being and parenting practices among single mothers. J Marriage Fam 55, 385-398.

92. Haycraft E, Farrow C \& Blissett J (2013) Maternal symptoms of depression are related to observations of controlling feeding practices in mothers of young children. $J$ Fam Psychol 27, 159-164.

93. Spillman D (1990) Survey of food and vitamin intake responses reported by university students experiencing stress. Psychol Rep 66, 499-502.

94. Warr P \& Payne R (1982) Experiences of strain and pleasure among British adults. Soc Sci Med 16, 1691-1697.

95. Stone AA \& Brownell KD (1994) The stress-eating paradox: multiple daily measurements in adult males and females. Psychol Health 9, 425-436.

96. Greeno CG \& Wing RR (1994) Stress-induced eating. Psychol Bull 115, 444-464.

97. Cartwright M, Wardle J, Steggles N, et al. (2003) Stress and dietary practices in adolescents. Health Psychol 22, 362-369.

98. Jackson JS, Knight KM \& Rafferty JA (2010) Race and unhealthy behaviors: chronic stress, the HPA axis, and physical and mental health disparities over the life course. Am J Public Health 100, 933-939.

99. Oliver G \& Wardle J (1999) Perceived effects of stress on food choice. Physiol Behav 66, 511-515.

100. Wardle J, Steptoe A, Oliver G, et al. (2000) Stress, dietary restraint and food intake. J Psychosom Res 48, 195-202.
101. Weinstein SE, Shide DJ \& Rolls BJ (1997) Changes in food intake in response to stress in men and women: psychological factors. Appetite 28, 7-18.

102. Koob GF \& Moal ML (2000) Drug addiction, dysregulation of reward, and allostasis. Neuropsychopharmacology $\mathbf{2 4}$, 97-129.

103. Milanes MV, Laorden ML, Chapleur-Chateau M, et al. (1998) Alterations in corticotropin-releasing factor and vasopressin content in rat brain during morphine withdrawal: correlation with hypothalamic noradrenergic activity and pituitary-adrenal response. J Pharmacol Exp Ther 285, 700-706.

104. Sinha R (2008) Chronic stress, drug use, and vulnerability to addiction. Ann N Y Acad Sci 1141, 105-130.

105. American Psychiatric Association (2006) Diagnostic and Statistical Manual of Mental Disorders (DSM-IV-TR), 4th ed., p. 356. Washington, DC: American Psychiatric Association.

106. Davis EP, Glynn LM, Waffarn F, et al. (2011) Prenatal maternal stress programs infant stress regulation. J Child Psychol Psychiatry 52, 119-129.

107. Essex MJ, Klein MH, Cho E, et al. (2002) Maternal stress beginning in infancy may sensitize children to later stress exposure: effects on cortisol and behavior. Biol Psychiatry 52, 776-784.

108. Lupien SJ, King S, Meaney KJ, et al. (2000) Child's stress hormone levels correlate with mother's socioeconomic status and depressive state. Biol Psychiatry 48, 976-980.

109. Golan M \& Crow S (2004) Parents are key players in the prevention and treatment of weight-related problems. Nutr Rev 62, 39-50.

110. Anzman SL, Rollins BY \& Birch LL (2010) Parental influence on children's early eating environments and obesity risk: implications for prevention. Int $J$ Obes (Lond) $\mathbf{3 4}$, 1116-1124.

111. Patrick H \& Nicklas TA (2005) A review of family and social determinants of children's eating patterns and diet quality. I Am Coll Nutr 24, 83-92.

112. Wroten K, O'Neil C, Stuff J, et al. (2012) Resemblance of dietary intakes of snacks, sweets, fruit, and vegetables among mother-child dyads from low income families. Appetite 59, 316-323.

113. Birch LL \& Fisher JO (1998) Development of eating behaviors among children and adolescents. Pediatrics 101, S539-S549.

114. Oliveria SA, Ellison RC, Moore LL, et al. (1992) Parent-child relationships in nutrient intake: the Framingham Children's Study. Am J Clin Nutr 56, 593-598.

115. Beydoun MA \& Wang Y (2009) Parent-child dietary intake resemblance in the United States: evidence from a large representative survey. Soc Sci Med 68, 2137-2144.

116. Hart CN, Raynor HA, Jelalian E, et al. (2010) The association of maternal food intake and infants' and toddlers' food intake. Child Care Health Dev 36, 396-403.

117. Busick D, Brooks J, Pernecky S, et al. (2008) Parent food purchases as a measure of exposure and preschool-aged children's willingness to identify and taste fruit and vegetables. Appetite 51, 468-473.

118. Sutherland LA, Beavers DP, Kupper LL, et al. (2008) Like parent, like child: child food and beverage choices during role playing. Arch Pediatr Adolesc Med 162, 1063-1069.

119. Wang Y, Li J \& Caballero B (2009) Resemblance in dietary intakes between urban low-income African-American adolescents and their mothers: the healthy eating and active lifestyles from school to home for kids study. J Am Diet Assoc 109, 52-63. 
120. Rossow I \& Rise J (1994) Concordance of parental and adolescent health behaviors. Soc Sci Med 38, 1299-1305.

121. Stafleu A, Van Staveren WA, de Graaf C, et al. (1994) Family resemblance in energy, fat, and cholesterol intake: a study among three generations of women. Prev Med 23, 474-480.

122. Vauthier JM, Lluch A, Lecomte E, et al. (1996) Family resemblance in energy and macronutrient intakes: the Stanislas Family Study. Int J Epidemiol 25, 1030-1037.

123. Laskarzewski P, Morrison JA, Khoury P, et al. (1980) Parent-child nutrient intake interrelationships in school children ages 6 to 19: the Princeton School District Study. Am J Clin Nutr 33, 2350-2355.

124. Fisher JO, Mitchell DC, Smiciklas-Wright H, et al. (2002) Parental influences on young girls' fruit and vegetable, micronutrient, and fat intakes. J Am Diet Assoc 102, 58-64.

125. Hoerr S, Nicklas T \& Liu Y (2009) Predictors of calcium intake at dinner meals of ethnically diverse mother-child dyads from families with limited incomes. J Am Diet Assoc 109, 1744-1750.

126. Fisher JO, Mitchell DC, Smiciklas-Wright H, et al. (2001) Maternal milk consumption predicts the tradeoff between milk and soft drinks in young girls' diets. J Nutr 131, 246-250.

127. Nicklas T, O'Neil C, Hughes S, et al. (2013) Resemblance of dinner meal consumption among mother and preschoolaged child dyads from families with limited incomes. Int J Child Health Nutr 2, 178-188.

128. Randall E, Marshall J, Graham S, et al. (1989) Frequency of food use data and the multidimensionality of diet. J Am Diet Assoc 89, 1070-1075.

129. Jeffery RW \& French SA (1998) Epidemic obesity in the United States: are fast foods and television viewing contributing? Am J Public Health 88, 277-280.

130. Poti J \& Popkin B (2011) Trends in energy intake among US children by eating location and food source, 1977-2006. J Am Diet Assoc 111, 1156-1164.

131. Drewnowski A \& Rehm CD (2013) Energy intakes of US children and adults by food purchase location and by specific food source. Nutr J 12, 59.

132. Powell L \& Nguyen B (2013) Fast-food and full-service restaurant consumption among children and adolescents: effect on energy, beverage, and nutrient intake. JAMA 167, 14-20.

133. Mancino L, Todd J \& Guthrie J, et al. (2010) How food away from home affects children's diet quality. USDA Economic Research Report no. ERR-104.

134. Hearst M, Harnack L, Bauer K, et al. (2013) Nutritional quality at eight US fast food chains: 14 year old trends. Am J Prev Med 44, 589-594.

135. Jaworowska A, Blackham T, Davies IG, et al. (2013) Nutritional challenges and health implications of takeaway and fast food. Nutr Rev 71, 310-318.

136. McCrory M, Fuss P, McCallum J, et al. (1999) Dietary variety within food groups: association with energy intake and body fatness in men and women. Am J Clin Nutr 69, 440-447.

137. Coll M, Meyer A \& Stunkard AJ (1979) Obesity and food choices in public places. Arch Gen Psychiatry 36, 795-797.

138. Ludwig DS, Peterson KE \& Gortmaker SL (2001) Relation between consumption of sugar-sweetened drinks and childhood obesity: a prospective, observational analysis. Lancet 357, 505-508.

139. Henry J \& Warren JJ (2001) Causes of obesity. Comment on: Relation between consumption of sugar-sweetened drinks and childhood obesity: a prospective, observational analysis. Lancet 357, 1978-1979.
140. Fishbein L (2001) Causes of obesity. Comment on: Relation between consumption of sugar-sweetened drinks and childhood obesity: a prospective, observational analysis. Lancet 357, 1978-1979.

141. Bellisle F \& Rolland-Cachera M (2001) How sugarcontaining drinks might increase adiposity in children. Comment on: Relation between consumption of sugarsweetened drinks and childhood obesity: a prospective, observational analysis. Lancet 357, 490-491.

142. Malik VS, Schulze MB \& Hu FB (2006) Intake of sugarsweetened beverages and weight gain: a systematic review. Am J Clin Nutr 84, 274-288.

143. Vartainian L, Schewartz M \& Brownell K (2007) Effects of soft drink consumption on nutrition and health: a systematic review and meta-analysis. Am J Public Health 97, 667-675.

144. Pereira MA \& Jacobs DR Jr (2008) Sugar-sweetened beverages, weight gain and nutritional epidemiological study design. Br J Nutr 99, 1169-1170.

145. Bachman CM, Baranowski T \& Nicklas TA (2006) Is there an association between sweetened beverages and adiposity? Nutr Rev 64, 153-174.

146. Gibson S (2008) Sugar-sweetened soft drinks and obesity: a systematic review of the evidence from observational studies and interventions. Nutr Res Rev 21, 134-147.

147. Mattes RD, Shikany JM, Kaiser KA, et al. (2011) Nutritively sweetened beverage consumption and body weight: a systematic review and meta-analysis of randomized experiments. Obes Rev 12, 346-365.

148. Libuda L \& Kersting M (2009) Soft drinks and body weight development in childhood: is there a relationship? Curr Opin Clin Nutr Metab Care 12, 596-600.

149. Van Baak M \& Astrup A (2009) Consumption of sugars and body weight. Obes Rev 10, 9-23.

150. Monasta L, Batty G, Cattaneo A, et al. (2010) Early-life determinants of overweight and obesity: a review of systematic reviews. Obes Rev 11, 695-708.

151. Olsen NJ \& Heitmann BL (2009) Intake of calorically sweetened beverages and obesity. Obes Rev 10, 68-75.

152. Wolff E \& Dansinger ML (2008) Soft drinks and weight gain: how strong is the link? Medscape J Med 10, 189.

153. Malik VS, Popkin BM, Bray GA, et al. (2010) Sugarsweetened beverages, obesity, type 2 diabetes mellitus, and cardiovascular disease risk. Circulation 121, $1356-1364$.

154. van Dam R \& Seidell J (2007) Carbohydrate intake and obesity. Eur J Clin Nutr 61, S75-S99.

155. Woodward-Lopez G, Kao J \& Ritchie L (2010) To what extent have sweetened beverages contributed to the obesity epidemic? Public Health Nutr 14, 499-509.

156. Edelman B, Engell D, Bronstein P, et al. (1986) Environmental effects on the intake of overweight and normal-weight men. Appetite 7, 71-83.

157. Booth DA, Fuller J \& Lewis V (1981) Human control of body weight: cognitive or physiological? Some energyrelated perceptions and misperceptions. In The Body Weight Regulatory System: Normal and Disturbed Mechanisms, pp. 305-314 [L Cioffi, WPT James and TB Van Itallie, editors]. New York, NY: Raven Press.

158. Rolls BJ (1995) Effects of food quality, quantity, and variety on intake. In Not Eating Enough, pp. 203-215 [BM Marriott, editor]. Washington, DC: National Academy Press.

159. Engell D, Kramer M, Zaring D, et al. (1995) Effects of serving size on food intake in children and adults. Obes Res 3, 381S. 
160. Rolls BJ, Engell D \& Birch LL (2000) Serving portion size influences 5-year-old but not 3-year-old children's food intakes. J Am Diet Assoc 100, 232-234.

161. Bradley PJ (1983) Food intake in the obese. Int J Obes 7 , 287-288.

162. Meguid MM, Laviano A \& Rossi-Fanelli F (1998) Food intake equals meal size times mean number. Appetite 31, 404.

163. Savage JS, Fisher JO, Marini M, et al. (2012) Serving smaller age-appropriate entree portions to children aged 3-5 y increases fruit and vegetable intake and reduces energy density and energy intake at lunch. Am J Clin Nutr 95, 335-341.

164. Hill JO \& Peters JC (1998) Environmental contributions to the obesity epidemic. Science 280, 1371-1374.

165. Siega-Riz AM, Carson T \& Popkin B (1998) Three squares or mostly snacks - what do teens really eat? A sociodemographic study of meal patterns. J Adolesc Health 22, 29-36.

166. Wolfe WS \& Campbell CC (1993) Food pattern, diet quality, and related characteristics of school children in New York State. J Am Diet Assoc 93, 1280-1284.

167. Wolfe WS, Campbell CC, Frongillo EA, et al. (1994) Overweight school children in New York State: prevalence and characteristics. Am J Public Health 84, 807-813.

168. Fabry P \& Tepperman J (1970) Meal frequency - a possible factor in human pathology. Am J Clin Nutr 23, 1059-1068.

169. Bellisle F, Rolland-Cachera MF, Deheeger M, et al. (1988) Obesity and food intake in children: evidence for a role of metabolic and/or behavioral daily rhythms. Appetite 11, 111-118.

170. Affenito SG, Thompson DR, Barton BA, et al. (2005) Breakfast consumption by African-American and white adolescent girls correlates positively with calcium and fiber intake and negatively with body mass index. $J$ Am Diet Assoc 105, 938-945.

171. Matthys C, De Henauw S, Bellemans M, et al. (2007) Breakfast habits affect overall nutrient profiles in adolescents. Public Health Nutr 10, 413-421.

172. Deshmukh-Taskar PR, Nicklas TA, O'Neil CE, et al. (2010) The relationship of breakfast skipping and type of breakfast consumption with nutrient intake and weight status in children and adolescents: The National Health and Nutrition Examination Survey 1999-2006. J Am Diet Assoc 110, 869-878.

173. Utter J, Scragg R, Mhurchu CN, et al. (2007) At-home breakfast consumption among New Zealand children: associations with body mass index and related nutrition behaviors. J Am Diet Assoc 107, 570-576.

174. Barton BA, Eldridge AL, Thompson D, et al. (2005) The relationship of breakfast and cereal consumption to nutrient intake and body mass index: the National Heart, Lung, and Blood Institute Growth and Health Study. J Am Diet Assoc 105, 1383-1389.

175. Timlin MT, Pereira MA, Story M, et al. (2008) Breakfast eating and weight change in a 5-year prospective analysis of adolescents: Project EAT (Eating Among Teens). Pediatrics 121, e638-e645.

176. Sandercock G, Voss C \& Dye L (2010) Associations between habitual school-day breakfast consumption, body mass index, physical activity and cardiorespiratory fitness in English schoolchildren. Eur J Clin Nutr 64, 1086-1092.

177. Baldinger N, Krebs A, Muller R, et al. (2012) Swiss children consuming breakfast regularly have better motor functional skills and are less overweight than breakfast skippers. $J \mathrm{Am}$ Coll Nutr 31, 87-93.
178. Berkey CS, Rockett HR, Gillman MW, et al. (2003) Longitudinal study of skipping breakfast and weight change in adolescents. Int J Obes Relat Metab Disord 27, 1258-1266.

179. Albertson A, Affenito S, Bauserman R, et al. (2009) The relationship of ready-to-eat cereal consumption to nutrient intake, blood lipids, and body mass index of children as they age through adolescence. J Am Diet Assoc 109, 1557-1565.

180. Albertson AM, Thompson D, Franko DL, et al. (2008) Consumption of breakfast cereal is associated with positive health outcomes: evidence from the National Heart, Lung, and Blood Institute Growth and Health Study. Nutr Res 28, 744-752.

181. Albertson AM, Anderson GH, Crockett SJ, et al. (2003) Ready-to-eat cereal consumption: its relationship with BMI and nutrient intake of children aged 4 to 12 years. J Am Diet Assoc 103, 1613-1619.

182. Albertson A, Thompson D, Franko D, et al. (2011) Weight indicators and nutrient intake in children and adolescents do not vary by sugar content in ready-to-eat cereal: results from National Health and Nutrition Examination Survey 2001-2006. Nutr Res 31, 229-236.

183. O'Neil C, Zanovec M, Nicklas T, et al. (2012) Pre-sweetened and non-pre-sweetened ready-to-eat cereals improve nutrient intake and diet quality without increasing body weight of children and adolescents: The National Health and Nutrition Examination Survey 1999-2002. Am J Lifestyle Med 6, 60-71.

184. de la Hunty A, Gibson S \& Ashwell M (2013) Does regular breakfast cereal consumption help children and adolescents stay slimmer? A systematic review and metaanalysis. Obes Facts 6, 70-85.

185. Brown AW, Bohan Brown MM \& Allison DB (2013) Belief beyond the evidence: using the proposed effect of breakfast on obesity to show 2 practices that distort scientific evidence. Am J Clin Nutr 98, 1298-1308.

186. Piernas C \& Popkin B (2010) Trends in snacking among U.S. children. Health Aff 29, 398-404.

187. Hampl JS, Heaton CL \& Taylor CA (2003) Snacking patterns influence energy and nutrient intakes but not body mass index. J Hum Nutr Diet 16, 3-11.

188. Kerver JM, Yang EJ, Obayashi S, et al. (2006) Meal and snack patterns are associated with dietary intake of energy and nutrients in US adults. J Am Diet Assoc 106, 46-53.

189. Cross AT, Babicz D \& Cushman LF (1994) Snacking patterns among 1800 adults and children. J Am Diet Assoc 94, 1398-1403.

190. Booth DA (1988) Mechanisms from models - actual effects from real life: the zero-calorie drink-break option. Appetite 11, 94-102.

191. Fabry P, Fodo J, Hejl Z, et al. (1964) The frequency of meals: its relation to overweight, hypercholesterolaemia, and decreased glucose tolerance. Lancet 2, 614-615.

192. Keast D, Nicklas T \& O'Neil C (2010) Snacking is associated with reduced risk of overweight and reduced abdominal obesity in adolescents: NHANES 1999-2004. Am J Clin Nutr 92, 428-435.

193. Summerbell CD, Moody RC, Shanks J, et al. (1996) Relationship between feeding pattern and body mass index in 220 free-living people in four age groups. Eur J Clin Nutr $\mathbf{5 0}$, 513-519.

194. Phillips SM, Bandini LG, Naumova EN, et al. (2004) Energydense snack food intake in adolescence: longitudinal relationship to weight and fatness. Obes Res 12, 461-472. 
195. Field AE, Austin SB, Gillman MW, et al. (2004) Snack food intake does not predict weight change among children and adolescents. Int J Obes Relat Metab Disord 28, 1210-1216.

196. Kant AK \& Graubard BI (2006) Secular trends in patterns of self-reported food consumption of adult Americans: NHANES 1971-1975 to NHANES 1999-2002. Am J Clin Nutr 84, 1215-1223.

197. Howarth NC, Huang TT, Roberts SB, et al. (2007) Eating patterns and dietary composition in relation to BMI in younger and older adults. Int J Obes (Lond) 31, 675-684.

198. Summerbell CD, Moody RC, Shanks J, et al. (1995) Sources of energy from meals versus snacks in 220 people in four age groups. Eur J Clin Nutr 49, 33-41.

199. Nicklas T, O’Neil C \& Fulgoni V III (2013) Relationship between snacking patterns, diet quality and risk of overweight and abdominal obesity in children. Int J Child Health Nutr 2, 189-200.
200. Nicklas TA, O’Neil CE \& Fulgoni VL III (2013) Snacking patterns, diet quality, and cardiovascular risk factors in adults. BMC Public Health 14, 388.

201. Blissett J \& Farrow C (2007) Predictors of maternal control of feeding at 1 and 2 years of age. Int J Obes (Lond) 31, $1520-1526$.

202. Goulding AN, Rosenblum KL, Miller AL, et al. (2014) Associations between maternal depressive symptoms and child feeding practices in a cross-sectional study of low-income mothers and their young children. Int J Behav Nutr Phys Act 11, 75-85.

203. Hurley KM, Black MM, Papas MA, et al. (2008) Maternal symptoms of stress, depression, and anxiety are related to nonresponsive feeding styles in a statewide sample of WIC participants. J Nutr 138, 799-805.

204. Lumeng JC, Ozbeki TN, Appugliese DP, et al. (2012) Observed assertive and intrusive maternal feeding behaviors increase child adiposity. Am J Clin Nutr 95, 640-647. 